\title{
STUDY OF ArF RESIST MATERIAL IN TERMS OF TRANSPARENCY AND DRY ETCH RESISTANCE
}

\author{
NAOMICHI ABE, SATOSHI TAKECHI, YUKO KAIMOTO, MAKOTO TAKAHASHI \\ AND KOJI NOZAKI*
}

Fujistu Limited

1015 Kamikodanaka, Nakahara-ku,Kawasaki 211,Japan

*Fujitsu Laboratories Limited

10-1 Morinosato-Wakamiya, Atsugi 243-01, Japan

\begin{abstract}
We investigated the etch rates of various polymers etch rates, and found that alicyclic polymers show a good dry etch resistance in spite of the lack of the aromatic rings. On the basis of this finding we proposed a new ArF resist material which has good transparency and good dry etch resistance for use as a single layer resist.. The resist comprises an alicyclic copolymer of adamantyl methacrylate (AdMA) and 3-oxocyclohexyl methaclyrate (OCMA) and a triphenylsulphonium hexafuluoroantimonate as a photoacid generator (PAG). The transmittance of the $1 \mu \mathrm{m}$ thick copolymer is about $70 \%$ at $\mathrm{ArF}$ wavelength. This high transparency ensures pattern imaging of the resist in ArF lithography. The dry etch resistance of the resist is also high and is comparable to that of Novolak resist. We obtained $0.17 \mu \mathrm{m}$ line and space patterns with this resist, using ArF excimer laser stepper.
\end{abstract}

\section{Introduction}

The drive toward continually higher integration of IC's requires smaller features in device fabrication. This demands improved resolution from lithographic technology. One of the most promising techniques to delineate less than quarter $\mu \mathrm{m}$ patterns is excimer laser lithography. Recent developments in $\mathrm{KrF}$ lithography combined with chemically amplified resists are remarkable. Only a few reports have been made, however, for ArF lithography, because of the lack of suitable resist [1-6]. Since the commonly used UV or KrF excimer resists contain aromatic rings to provide dry-etch resistance, they cannot be used for $\mathrm{ArF}$ lithography due to the high absorbance of their aromatic rings at $193 \mathrm{~nm}$. Therefore, early application of ArF lithography has been limited to surface imaging or bilayer resist system [1-3]. Recently chemically amplified resists composed of acrylate polymers have been shown to serve as single layer [4-6]. However, they are not suitable for practical use, since the dry-etch resistance is poor. Therefore, a new resist with both high transparency and high dry-etch resistance is highly required.

For this purpose we first investigated etching rates of various polymers, and found alicyclic polymers show high dry-etch resistance. One the basis of this founding, we designed a ArF resist. 
The resist is composed of a co-polymer of adamantyl methacrylate and 3-oxocyclohexyl methaclylate and a PAG [7-9].

In this paper we will review our study on ArF resist material and also report recent results of evaluating our resist using ArF stepper.

\section{Experiment}

We prepared poly methylmethacrylate (PMMA), poly tert-butylmethacry-late (PtBuMA), poly cyclohexylmethacrylate (PCHMA), poly norbonylmethacry-late (PNBMA), poly adamantylmethacrylate (PAdMA), poly benzylmthacrylate (PBnMA) and the copolymer of adamantylmethacrylate and 3-oxocyclohexylmehacrylate (poly (AdMA-OCMA)\} for our investigation. All polymers were prepared by thermally induced free radical polymerization using AIBN (2,2'azobis-isobutyronitrile). Other polymers and chemicals used were obtained commercially.

We investigated polymer's etch rates using a reactive ion etching machine made in house. Lithographic experiments were conducted on a NICON plot-type ArF excimer stepper (NA=0.55).

\section{Results and Discussion}

We first investigated the etch rates of various polymers. The result is summarized in Fig. 1. The etch rates of the polymers which contain aromatic rings show low etch rates as expected. It is to be noted that the polymers which contain alicyclic rings also show low etch rates in spite of their lack of aromatic rings.

To confirm our finding that the alicyclic polymers show low etch rates and hence have high dry etch resistance, we further investigated the etch rates of PMMA, PtBuMA, PCHMA, PNBMA, PAdMA and PBnMA in comparison with Novolak resist (Table 2). Alicyclic polymers such as PCHMA, PNBMA and PAdMA have good dry etch resistance for both $\mathrm{CF}_{4}$ and Ar etching gases. Furthermore their dry etch resistance increases according to the number of cyclohexyl rings in the alicyclic hydrocarbon, and especially notable, the dry etch resistance of PAdMA is better than that of the polymers which have aromatic rings such as PBnMA and Novolak resist. This shows that the norbornane or adamantane works as a resistant group just as the aromatic ring in the dry etching.

On the basis of the investigation described above, we designed a ArF single layer resist system. The resist comprises the copolymer of adamantylmethacrylate (AdMA) and 3oxocyclohexylmethacrylate (OCMA) with triphenyl sulfonium hexafluoro-antimonate (Ph3SSbF6) as the PAG (Fig.2) 


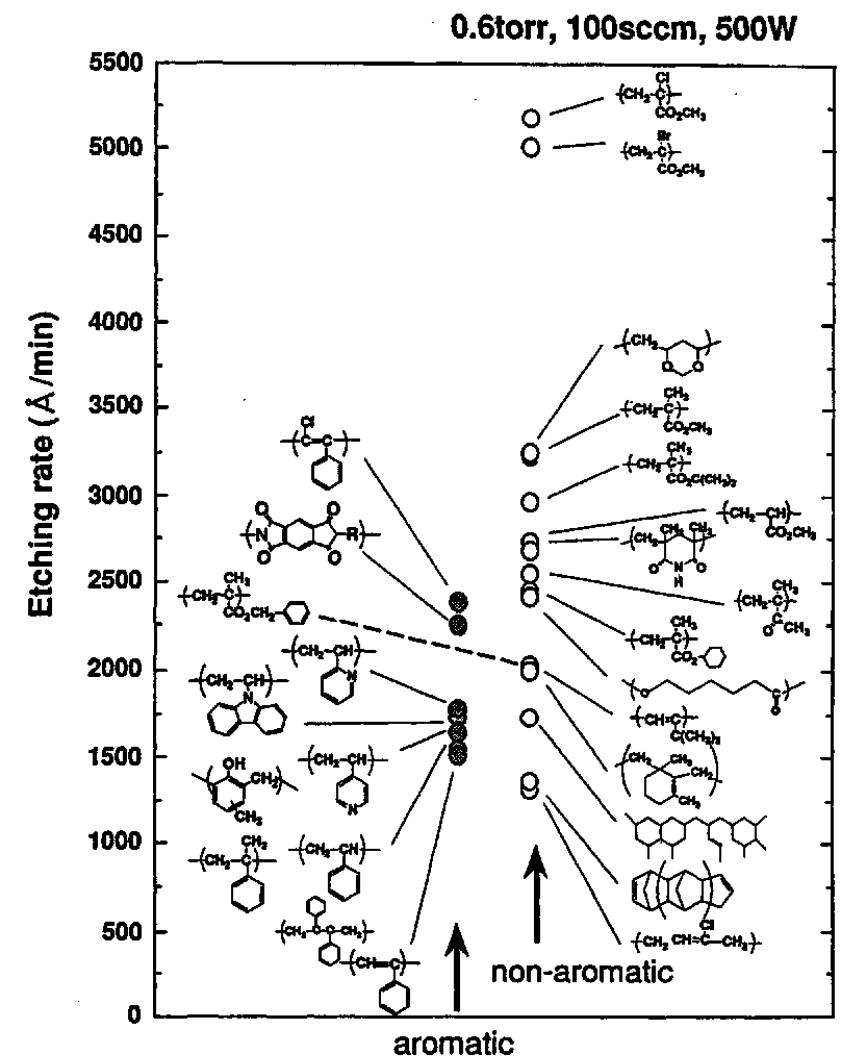

Fig. 1. Etch rates of polymers with $\mathrm{CF}_{4}$ etching gas.

\begin{tabular}{|c|c|c|}
\hline \multirow{2}{*}{ Polymers } & Ar & CF4 \\
\hline & \multicolumn{2}{|c|}{$100 \mathrm{sccm}, 0.02$ torr, $200 \mathrm{~W}$} \\
\hline 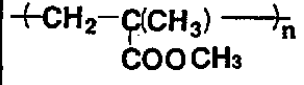 & 2.10 & 1.53 \\
\hline 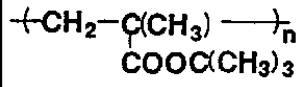 & 2.07 & 1.41 \\
\hline $\begin{array}{r}+\mathrm{CH}_{2}-\mathrm{C}_{\mathrm{COO}}\left(\mathrm{CH}_{3}\right)- \\
\mathrm{COO}\end{array}$ & 1.53 & 1.24 \\
\hline $\begin{array}{c}+\mathrm{CH}_{2}-\mathrm{COO}_{\mathrm{C}}\left(\mathrm{CH}_{3}\right) \\
-\end{array}$ & 1.48 & 1.14 \\
\hline $\begin{array}{r}+\mathrm{CH}_{2}-\mathrm{C}\left(\mathrm{CH}_{3}\right)- \\
\mathrm{COO}\end{array}$ & 0.99 & 0.97 \\
\hline $\begin{array}{r}\left.+\mathrm{CH}_{2}-\mathrm{C}_{\mathrm{COOCH}} \mathrm{CH}_{2}\right)- \\
\mathrm{COOH}\end{array}$ & & 1.08 \\
\hline Novolac resist & 1.00 & 1.00 \\
\hline
\end{tabular}

Table 1. Etch rates of methacrylate with $\mathrm{CF}_{4}$ and Ar etching gases.

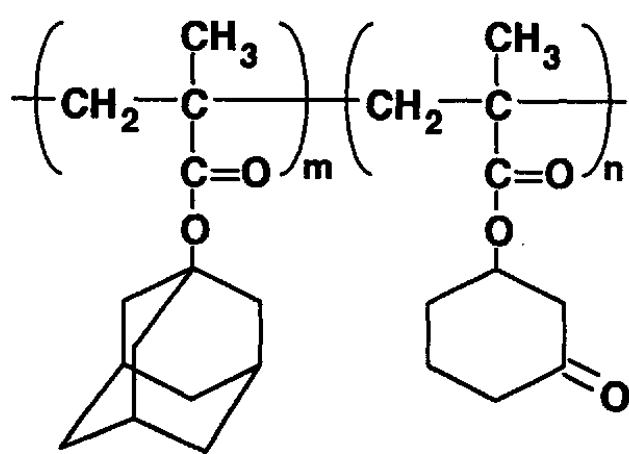

(a)<smiles>O=S(=O)(c1ccccc1)c1ccccc1</smiles>

(b)

Fig. 2. Resist structure: (a) the base polymer (b) the PAG 
The AdMA unit in the polymer chain provides good dry etch resistance. The 3oxocyclohexyl esters moiety in the methacrylate unit provides facile acidolysis and therefore a polarity change for imaging. $\mathrm{Ph}_{3} \mathrm{SSbF}_{6}$ generates a strong acid upon irradiation to initiate the elimination reaction shown in Fig.3.

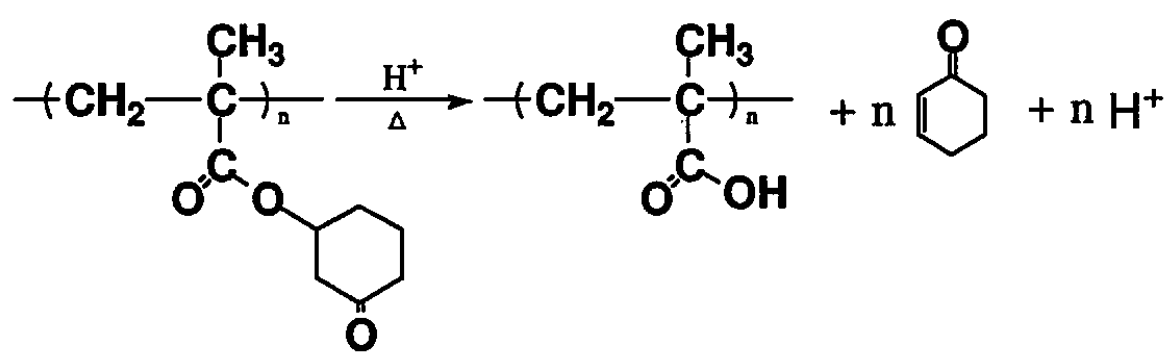

Fig. 3. Pathway for the acid-catalyzed deprotection and regeneration of a proton

Fig. 4 shows the UV-VUV spectra of poly (AdMA-OCMA) and poly vinyl phenol (PVP), which is used commonly as a base polymer for $\mathrm{KrF}$ resist, for comparison. The transmittance of poly (AdMA-OCMA) is about 70\% at ArF wavelength (193nm), while PVP is completely opaque at ArF wavelength.

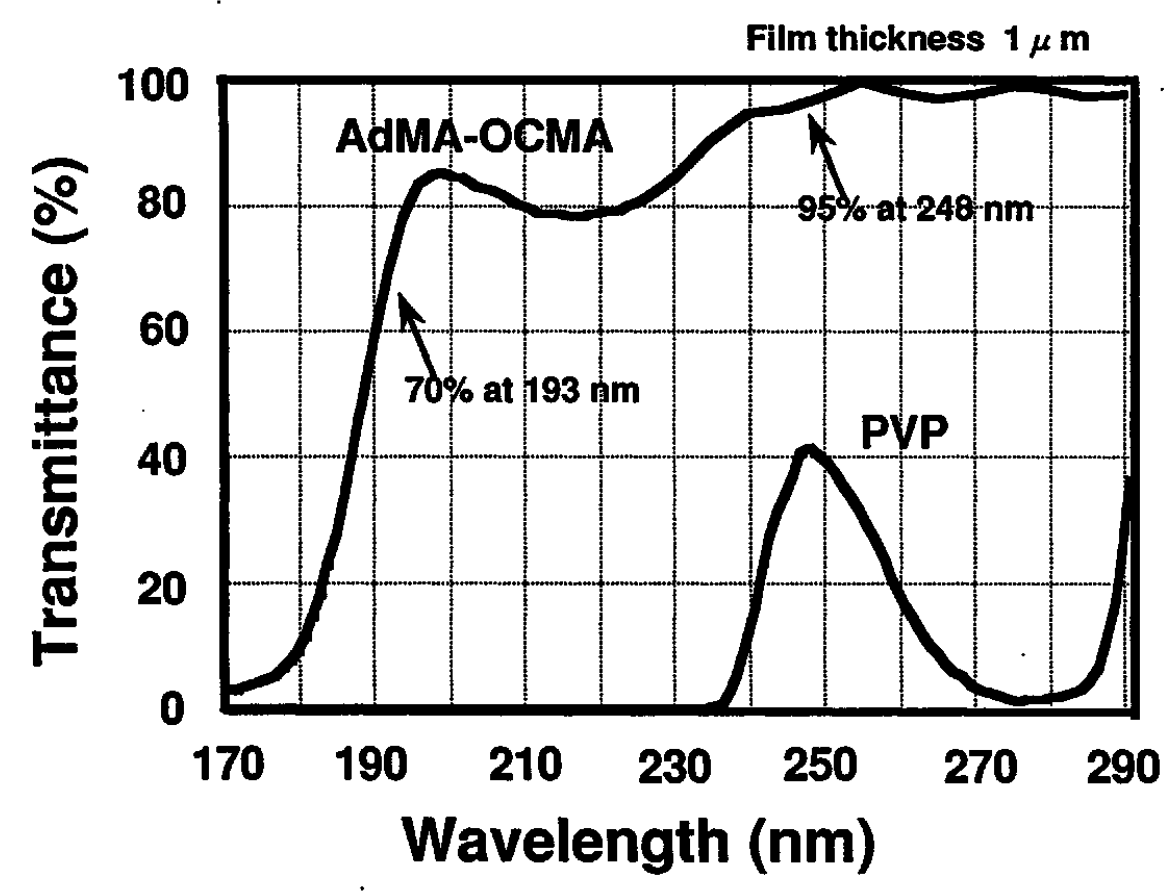

Fig. 4. UV-VUV spectra of poly (AdMA-OCMA) and PVP. 
We examined the etch rates of $\mathrm{AdMA}_{60}-\mathrm{OCMA}_{40}$ copolymer for $\mathrm{CF}_{4}$ and Ar etching gases. The results are shown in Table 2, along with the etch rates of PMMA and Novolak resin for comparison. These values are normalized to that of Novolak resist. As seen in the table, the dry etch resistance of AdMA-OCMA copolymer is almost equal to Novolak resins in spite of the lack of aromatic rings.

\begin{tabular}{c||c|c} 
& $\mathrm{CF}_{4}$ & $\mathrm{Ar}$ \\
\hline \hline Novolac resin & 1.0 & 1.0 \\
\hline OCMA-AdMA copolymer & 0.9 & 1.1 \\
\hline PMMA & 1.4 & 2.0 \\
\hline
\end{tabular}

Table 2. Dry etch resistance of PMMA and poly (AdMAOCMA) in comparison with Novolak resin

The resist which comprises poly (AdMA60-OCMA40) with $\mathrm{Ph}_{3} \mathrm{SSbF}_{6}(1 \mathrm{wt} \%)$ as the PAG was evaluated. The $0.4 \mu \mathrm{m}$ thick resist was exposed with a ArF excimer stepper. The resist was baked at the temperature of 150 centidegree and then developed in 1:4 mixture of isopropyl alcohol and $2.38 \%$ TMAH (tetra methyl ammonium hydroxide) solution. The $0.17 \mu \mathrm{m}$ lines and spaces were resolved (Fig.5).

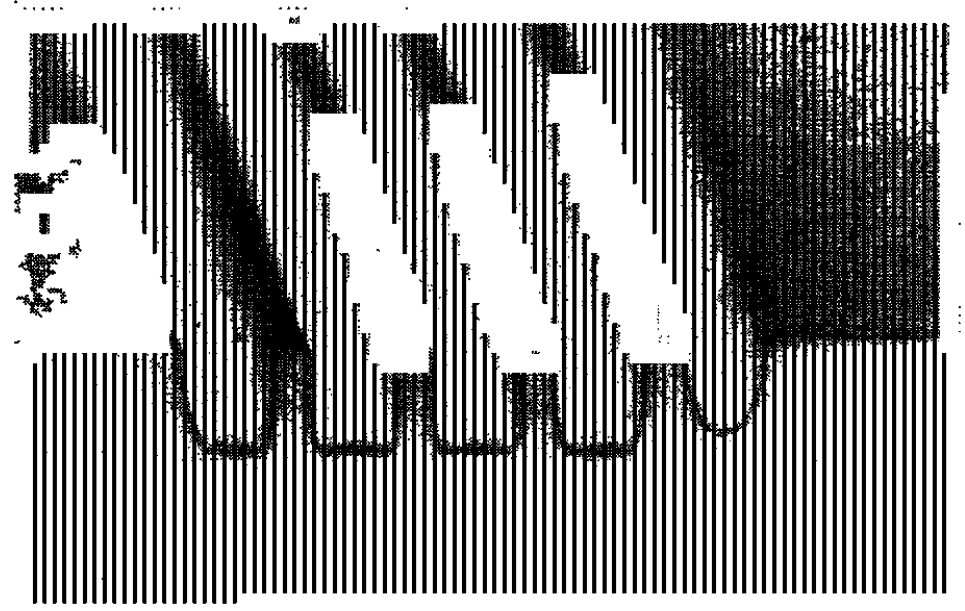

Fig. 5. Resist patterns of $0.17 \mu \mathrm{m}$ lines and spaces. 


\section{References}

1. M. A Hartney,P. R. Kunz,D. J. Ehrich and D. C. Shaver, Proc. SPIE, $1262(1990) 119$.

2. R.R.Kunz, M.W.Horn, R.B.Goodman, P.A. Bianconi,D.A.Smith, J. R. Eshelman, G. M. Wallraf, R. D. Miller and E. J. Ginsburg, Proc. SPIE,1672(1992)385.

3. G. M. Wallraff, R. D. Miller, M. Baier, E.J. Ginsburg and R. R. Kunz, J. Photopolym, Sci. Technol. 5(1992)111.

4. R. R. Kunz, R. D. Allen, W. D. Hinsberg and G. M Wallraf, Proc. SPIE, 1925(1993) 167.

5. R. R. Kunz, M. A. Hartney, M. W. Horn, C. L. Keast, M. Rothschild and D. C. Shaver, J. Photopolym. Sci. Technol. 6(1993)473.

6. R. D. Allen, G. M. Wallraf, W. E. Conley and R. R. Kunz, J. Photopolym. Sci. Technol., 6(1993)575.

7. Y. Kaimoto, K. Nozaki, S. Takechi and N. Abe, Proc. SPIE, 1672(1992)66.

8. K. Nozaki, Y, Kaimoto, M. Takahashi, S. Takechi and N. Abe, Chem. Mater. 6(1994)1492

9. M. Takahashi, S. Takechi, K. Nozaki, Y. Kaimoto and N. Abe, J. Photopolym. Sci. Technol, $7(1994) 31$. 